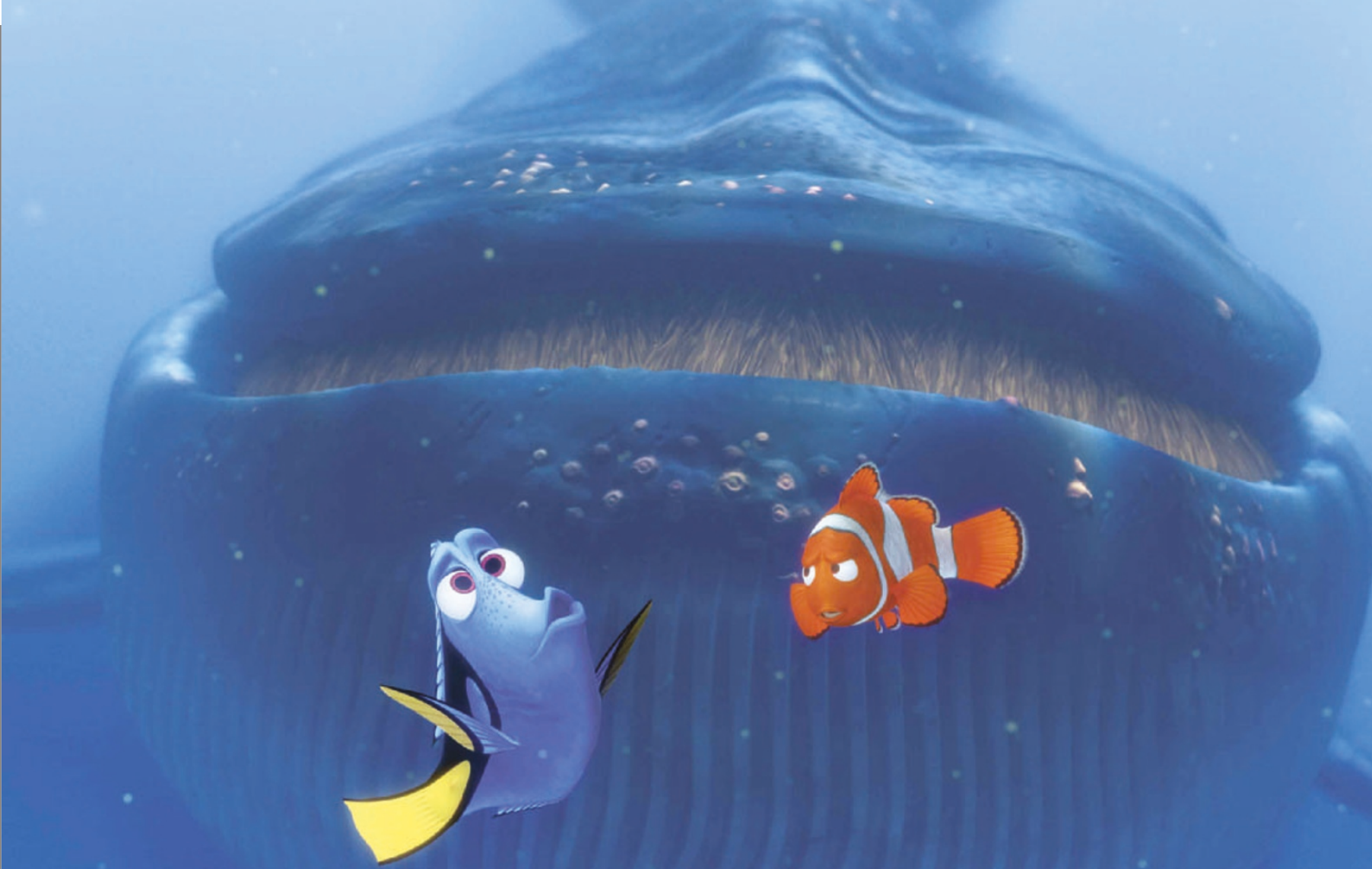

\title{
The fabulous fish guy
}

\section{Last year's movie smash Finding Nemo impressed many marine biologists with its scientific accuracy. Alison Abbott meets the young expert in fish biomechanics who helped to breathe life into the film's stars.}

A dam Summers doesn't own a television. And he had never seen an animated movie until a chance encounter propelled him into the studios of Pixar, as scientific adviser on the company's film, Finding Nemo.

The film tells a stirring tale of the efforts of Marlin, a widowed barrier-reef clown fish, to rescue his only son Nemo who has been 'abducted', and taken to live in a dental surgery's aquarium in Sydney. It was the highest-grossing film of 2003, and is in contention for four Oscars at the Annual Academy Awards on 29 February.

In early 2000, Summers was beginning a postdoc in fish biomechanics at the University of California, Berkeley. He rented an apartment owned by a woman who was an art teacher at Pixar. At that time, the studio had just approved a script starring a fish — and the director and animators urgently wanted to know more about their subject matter.
Summers' landlady acted as a go-between, and invited him to give a lecture.

Summers didn't know quite what to expect when he first stepped in front of director and scriptwriter Andrew Stanton and his team in the luxurious screening rooms of the Pixar studios in Emeryville, California. But the film-makers devoured his words like sharks in a feeding frenzy. Summers told them about fish locomotion, behaviour, physiology and coloration. "It was the most engaged class I've ever taught," he says. "I could only get out two or three sentences before a hand would shoot up - and it was graduate-level stuff."

\section{Tales from the deep}

Summers also talked about fish oddities, such as the deep-sea anglerfish that live in such darkness that finding a mate is difficult. The tiny males swim up trails of pheromones left by the large females, and then latch on to them so tightly that they eventually grow into each other. The male becomes little more than a parasitic testicle, able to fertilize eggs whenever the female is ready to lay them. "They loved these stories," says Summers, who is now an assistant professor at the University of California, Irvine. "My one-hour lecture stretched to two and a half hours."

He thought that would be it, but two days later, his landlady knocked on his door again: the studio wanted more. And so Summers found himself giving a three-year course in ichthyology. He organized some 20 lectures on subjects ranging from swimming mechanics to the social behaviour of fish. Some of the topics he suggested himself; others were requested by Pixar employees. All of the talks were recorded so that newcomers could catch up, but Summers was still asked to repeat somelectures - such as his popular discourse on fish locomotion - two or three times.

"In every movie, you need as much research as possible: for every fact you use, you have ten more you need to know about," says Stanton. "We had to traverse a whole ocean in the movie, so we needed a lot of knowledge."

Summers even organized a few makeshift 'labs'. Light quality is immensely important for animators, particularly the 'shaders' who have to worry about how light is reflected from surfaces. So they wanted to know, in huge detail, how fish scales reflect light. Summers brought in a selection of different fish and some microscopes, set up trestle tables and launched into a practical dissecting class 
